\title{
Medindo a fidelidade das torcidas brasileiras: uma análise econômica no futebol $^{*}$
}

\author{
Bruno Giovannetti ${ }^{\dagger}$, Bruno de Paula Rocha ${ }^{\ddagger}$, Fábio Miessi Sanches ${ }^{\S}$, \\ José Carlos Domingos da Silva
}

Sumário: 1. Introdução; 2.0 modelo teórico; 3. Estimação e resultados; 4. Conclusão; A. Apêndice. Palavras-chave: microeconomia; economia do esporte; modelos Logit multivariados e ordenados; modelos em painel.

Códigos JEL: D11; D12; L83; C33; C35.

Este trabalho modela o comportamento de torcidas do futebol profissional brasileiro no que se refere à presença nos estádios. A partir daí, busca testar a fidelidade das mesmas no campeonato brasileiro de 2004. Para isso estima, para os grandes times nacionais, quais foram as torcidas cujo número de torcedores presentes nos jogos pode ser explicado pela expectativa da torcida com relação ao resultado do jogo. Assim, dois passos são seguidos, ambos baseados no nacional de 2004: o primeiro procura estimar, jogo a jogo, um vetor de probabilidade de vitória, empate e derrota do time, através de um Logit Ordenado; o segundo busca estimar, torcida a torcida, quais têm a presença nos estádios determinada pela expectativa percebida com relação ao resultado do jogo. Para tal campeonato, apenas 3 torcidas aparecem como infiéis, quais sejam, dos clubes Atlético Mineiro, Grêmio e Internacional de Porto Alegre.

This paper models the behavior of the Brazilian professional football's fans concerning their presence in the stadiums. So, it aims to test the fidelity of them in the 2004 National League. In this direction, it estimates, regarding the twelve biggest teams, for which fans the expectation about the games's result is able to

\footnotetext{
*Os autores agradecem aos comentários de Denisard Alves, Márcio Nakane, Carlos Eduardo Gonçalves e Igor Viveiros Souza. Como de praxe, todos os erros remanescentes são de nossa inteira responsabilidade.

${ }^{\dagger}$ Mestre em Economia pelo IPE-FEA-USP.

${ }^{\ddagger}$ Doutorando em Economia pelo IPE-FEA-USP.

$\S_{\text {Mestre em Economia pelo IPE-FEA-USP. }}$

${ }^{\top}$ Mestre em Economia pelo IPE-FEA-USP.
} 
explain their presence in the stadiums. Hence, it follows two steps, both about the 2004 National Championship: first, it estimates, game by game, a vector with the win, loss and tie probabilities, using a Ordered Logit; second, it tries to capture for which teams fans this vector are able to explain their presence in the stadiums. For the championship said above, only three teams have non-loyalty fans: Atlético Mineiro, Grêmio and Internacional de Porto Alegre.

\section{INTRODUÇÃO}

"Art. $2^{0}$ : Torcedor é toda pessoa que aprecie, apóie ou se associe a qualquer entidade de prática desportiva do País e acompanhe a prática de determinada modalidade esportiva." Estatuto do Torcedor - Lei no. 10.671, de 15 de maio de 2003.

O Brasil é o país do futebol. Esta é uma afirmação que pode ser feita sem muitas controvérsias. Prova disso é a liderança no ranking da FIFA há mais de 10 anos, corroborada por cinco campeonatos mundiais conquistados pelo país. Soma-se a isso a reputação de maior exportador de jogadores no mundo, cerca de 1.100 entre janeiro de 2004 e maio de 2005, com destinos variando de países tradicionais, como Portugal, Espanha e Itália, a campos menos favorecidos, como Finlândia ou Bósnia-Herzegovina.

Por outro lado, longe dos gramados, o futebol pentacampeão tem se mostrado um fracasso empresarial. Como mostram os dados apresentados por Souza (2004), houve uma significativa queda na média de público do Campeonato Brasileiro, passando de 16.256 e 16.102 nas décadas de 70 e 80 para cerca de 12.219 a partir dos anos 90 . Além disso, o elevado endividamento dos clubes e a incapacidade de segurar os principais jogadores são outras das características pouco lisonjeiras que podem ser citadas. 0 fato é que nunca houve muita preocupação com aspectos técnico-administrativos fora de campo. Tampouco parece ter havido muito empreendimento acadêmico que tentasse explicar em bases científicas os fenômenos econômicos por trás do futebol. Apesar disso, alguns trabalhos devem ser citados, como Araújo Jr. et alii (2003) e Shikida e Shikida (2004). No primeiro trabalho, os autores tentam desvendar os fatores determinantes de uma campanha de sucesso no Campeonato Brasileiro. Shikida e Shikida (2004), por sua vez, procuram verificar se os jogos de futebol podem funcionar como uma "válvula de escape" para apertos tributários. Outras referências que merecem destaque são Melo (2003) e Amador (2004), que têm um enforque essencialmente contábil, além do já citado Souza (2004), que estuda os determinantes do público pagante no Campeonato Brasileiro de 2002.

Esta escassez de pesquisa econômica a respeito do futebol brasileiro acaba por mostrar-se injustificável, pois, além da importância cultural, social e econômica deste esporte, a massa de dados disponível faria deste campo um laboratório ideal para avaliação de várias predições teóricas. Este assunto, no entanto, tem sido alvo de extenso estudo em outros países. A economia do futebol, como costuma ser chamada esta área de pesquisa, remonta ao trabalho seminal de Rottenberg (1956). Neste trabalho, o autor apresenta as características básicas da economia dos esportes profissionais, em especial a natureza conjunta do processo de produção esportiva. Neste sentido, no futebol, bem como nos demais esportes profissionais, uma única equipe é incapaz de produzir o “bem final” partida - é necessário, portanto, que haja disputa e equilíbrio entre as forças que disputam uma competição profissional.

A existência da concorrência esportiva é um imperativo para a sobrevivência econômica das equipes profissionais. Todavia, há que se distinguir entre concorrência econômica e concorrência esportiva, tal como propôs Neale (1964). O fato de uma equipe profissional não conseguir sobreviver sozinha num ambiente esportivo não implica que o monopólio econômico seja menos lucrativo que a concorrência econômica no futebol e nos demais esportes profissionais. Neale (1964) argumenta que a Liga das equipes profissionais é que deve ser considerada como agente econômico relevante. Seguindo este argumento, as equipes seriam como plantas produtivas de uma Liga que detém um monopólio natural na organização das competições do esporte em questão. 
No entanto, a hipótese de que as Ligas devam ser consideradas como a unidade econômica relevante é controversa. Outros autores, como Sloane (1971), argumentam que as próprias equipes profissionais devem ser consideradas como unidades maximizadoras de utilidade. Muito se produziu em economia do futebol após estas contribuições seminais. Uma descrição da literatura teórica e empírica surgida após os anos 70, com enfoque para a Liga Inglesa de futebol, pode ser vista no recente trabalho feito por Dobson e Goddard (2001).

O presente trabalho insere-se neste contexto, mas discutindo questões associadas à demanda por serviços esportivos, em especial por jogos de futebol. Neste ponto, faz-se necessário apresentar outra característica peculiar à economia do futebol: uma elevada interação entre demanda e oferta (Neale, 1964). Quem já foi a um estádio de futebol pode imaginar facilmente o sentido desta afirmação. Para entender como isso acontece, tomemos o desempenho do clube como uma proxy para a produção. Do hino cantado em uníssono às bandeiras empunhadas, várias são as maneiras pela qual o torcedor "demandante" pode influenciar a "produção" de nosso bem final desempenho da equipe. Por outro lado, é fácil imaginar o poder de uma bela campanha em fazer ressoar feliz o hino do clube por todo o estádio e atrair a torcida. Mas, atrairia mesmo? Seria a apaixonada torcida brasileira sensível ao desempenho de seu clube do coração? Muitas torcidas no Brasil têm sido rotuladas de "fiéis", enquanto outras acompanhariam seus clubes apenas nos bons momentos. No entanto, nenhuma análise formal dos dados foi levada a cabo para avaliar tais comportamentos.

O objetivo deste trabalho é avaliar o grau de fidelidade do torcedor brasileiro, usando dados para o Campeonato Brasileiro de 2004. Fidelidade aqui é entendida em termos de sensibilidade do torcedor à probabilidade de um bom desempenho de seu clube.

Em nosso modelo teórico, o torcedor é representado por um agente econômico maximizador de utilidade que escolhe entre ir ou não ao estádio de futebol. A utilidade derivada do jogo de futebol depende essencialmente do resultado da partida: é sempre melhor que seu time vença. No entanto, o resultado da partida não é conhecido no momento da decisão entre ir ou não ao estádio. Tal fato torna relevante a probabilidade esperada (ex-ante) pelo torcedor de um bom desempenho de seu time. A fidelidade é então definida em termos da natureza do efeito desta probabilidade sobre a decisão de ir ou não ao estádio de futebol. Este modelo é apresentado em detalhes na próxima seção.

Em seguida, a terceira seção apresenta a estratégia de estimação e os principais resultados obtidos. A análise empírica constitui-se primordialmente da avaliação da significância estatística do vetor de probabilidades de vitória, empate e derrota na determinação do público presente ao estádio. Como já ressaltado, estas probabilidades podem ser afetadas pelo próprio público presente, de forma que, para se evitar o problema de endogeneidade, o procedimento foi dividido em dois passos. Em um primeiro momento, assumimos a hipótese de identificação de que a probabilidade esperada de vitória, empate ou derrota em um determinado jogo é feita com base no conjunto de informação disponível até o jogo anterior. Assim, num procedimento recursivo, a cada rodada, as probabilidades foram estimadas usando-se um modelo Logit multinomial e ordenado, em que a amostra era constituída pelos jogos das rodadas anteriores. Como teste de robustez, foram testadas as memórias de 40, 20, 10 e 5 rodadas anteriores. $\mathrm{O}$ vetor de probabilidades encontrado neste passo é utilizado no segundo estágio para, em um modelo de painel, identificar as torcidas cuja sensibilidade a este vetor permite-nos classificá-las como infiéis.

Por último, são apresentadas as principais conclusões e sugestões para possíveis extensões ao trabalho.

\section{O MODELO TEÓRICO}

Esta seção terá como objetivo modelar teoricamente a questão da escolha do consumidor, envolvida na decisão do torcedor ir ou não ao estádio de futebol. A partir daí, será apresentada formalmente a definição de fidelidade do torcedor utilizada no decorrer desse trabalho. 
Como o problema aqui colocado trata da escolha de consumo por um único bem, o qual representa, via de regra, uma pequena parcela do orçamento de cada consumidor, será utilizada a abordagem de equilíbrio parcial. Nela, o agente optará entre o consumo de jogo de futebol e dinheiro, sob um ambiente quase-linear. A principal característica de um ambiente quase-linear é que não há efeito renda no consumo do bem. Assim, tal função dá conta da hipótese de que o consumo de jogo de futebol corresponde a uma pequena parcela da renda do indivíduo ${ }^{1}$.

Posto isso, temos então seguinte função utilidade de cada indivíduo:

$$
u(x, m)=m+\phi(x)
$$

onde $x$ representa a quantidade de jogo de futebol e m representa o numerário.

Vale aqui uma discussão sobre a variável $x$. Como a escolha final do agente é binária (ou ele vai, ou ele não vai ao estádio) mas, na resolução do problema do consumidor $x$ é uma variável contínua, a questão será colocada da seguinte maneira: encarar-se-á $x$ como uma variável latente, a qual, além de determinada fronteira exógena, que será chamada de $\theta$, implica na escolha do indivíduo por ir ao estádio; do contrário, sua escolha será ficar em casa. Assim temos:

$$
y=\left\{\begin{array}{l}
1, x \geq \theta \\
0, c c
\end{array}\right.
$$

onde, para $\phi$ igual à 1 , o torcedor vai ao jogo e para $\phi$ igual à 0 ele não vai.

Assim, voltemos à função utilidade. Três estados da natureza são possíveis: a vitória, o empate ou a derrota do time do agente. A princípio, é razoável supor que um jogo que o agente escolheu consumir lhe dará utilidades diferentes, a depender do estado da natureza realizado (a vitória de seu time lhe dará uma utilidade diferente do empate e da derrota, por exemplo). Deste modo, o que temos são três funções utilidade distintas, uma para cada um dos possíveis estados da natureza.

$$
\begin{aligned}
& u^{V}(x, m)=m+\phi^{V}(x) \\
& u^{E}(x, m)=m+\phi^{E}(x) \\
& u^{D}(x, m)=m+\phi^{D}(x)
\end{aligned}
$$

onde os indexadores $V, E$ e $D$ correspondem à vitória, ao empate e à derrota, respectivamente.

O problema de escolha do consumidor cai desta maneira num ambiente de incerteza onde, grosso modo, a decisão de ir ao estádio poderia ser encarada como um loteria. Assim, a otimização da utilidade por parte do consumidor passa pela abordagem da utilidade esperada, cujo trabalho seminal é o de Neumann e Morgenstern (1944).

O agente tem então o seguinte problema a ser resolvido:

$$
\begin{gathered}
\operatorname{Max}_{x, m}\left\lfloor\pi^{V} u^{V}(x, m)+\pi^{E} u^{E}(x, m)+\pi^{D} u^{D}(x, m)\right\rfloor \\
\pi^{V}+\pi^{E}+\pi^{D}=1 \\
m+x p_{x}=y
\end{gathered}
$$

onde $\pi^{G}, \pi^{E}$ e $\pi^{V}$ representam as probabilidade de vitória, empate e derrota, respectivamente, $p_{x}$ representa o custo unitário da variável latente $x$ e $y$ representa a renda do consumidor.

A solução de tal problema, o par $\left(x^{*}, m^{*}\right)$, é:

$$
\left\{\begin{array}{l}
x^{*}=x, \text { tal que } \pi^{V} \phi^{\prime V}(x)+\pi^{E} \phi^{\prime E}(x)+\left(1-\pi^{V}-\pi^{E}\right) \phi^{D}(x)=p_{x} \\
m^{*}=y-x^{*} p_{x}
\end{array}\right.
$$

\footnotetext{
${ }^{1}$ Uma boa apresentação de equilíbrio parcial e de seu tratamento via função utilidade quase linear se encontra em Mas-Colell et alii (1995, cap. 10)
} 
Como descrito anteriormente, temos que se $x^{*}$ é maior do que $\theta$, o agente escolhe ir ao jogo; caso contrário ele escolhe não ir.

Façamos agora algumas considerações algébricas sobre a função utilidade. Em primeiro lugar é razoável supor que $\phi^{\prime V}(x) \geq \phi^{\prime E}(x) \geq \phi^{\prime D}(x)$, para qualquer $x$, o que implica que as utilidades marginais nunca se cruzam - mais à frente, será discutida a desigualdade estrita entre as utilidades marginais para cada estado da natureza a despeito da igualdade. Em segundo lugar, será assumida utilidade marginal decrescente para $x$. Para a representação gráfica do problema do consumidor, imporemos também que as utilidades marginais são lineares (isso será feito apenas para tornar a representação gráfica mais clara, sem ter, entretanto, qualquer conseqüência na discussão que se segue).

Assim, a solução do problema do consumidor pode ser representada graficamente de acordo com a Figura 1.

Figura 1 - Solução do problema do consumidor

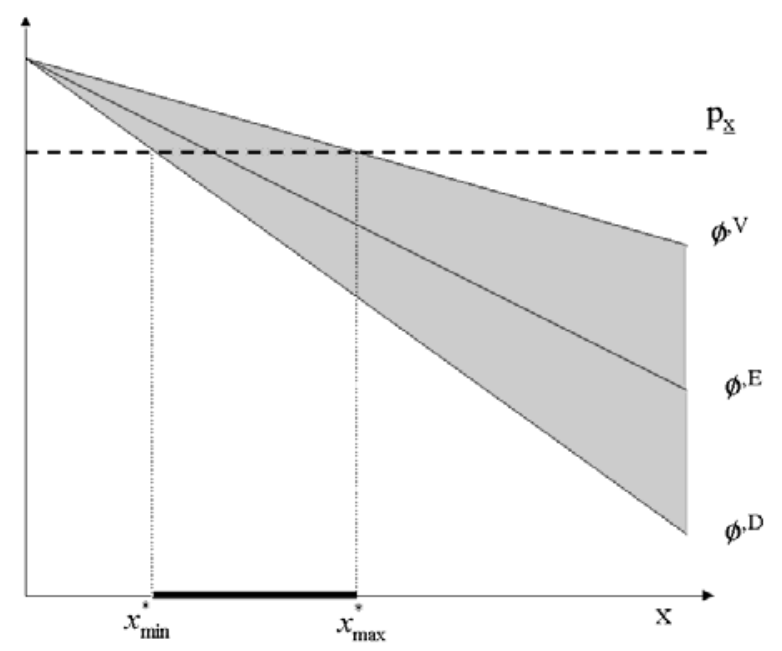

A área marcada em cinza é onde a função de utilidade marginal esperada, $U M E=\pi^{V} \phi^{\prime V}(x)+$ $\pi^{E} \phi^{\prime E}(x)+\left(1-\pi^{V}-\pi^{E}\right) \phi^{\prime D}(x)$, pode se localizar. Para $\pi^{V}=1$, teremos $U M E(x)=\phi^{\prime V}(x)$, para qualquer $x$; para $\pi^{D}=1$, teremos $U M E(x)=\phi^{\prime D}(x)$, para qualquer $x$; caso contrário, teremos $\phi^{\prime D}(x)<U M E(x)<\phi^{\prime V}(x)$, para qualquer $x$. Deste modo, concluímos que a solução pertencerá ao intervalo marcado em negrito no gráfico, ou seja, $x^{*} \in\left\lfloor x_{M I N}^{*}, x_{M A X}^{*}\right\rfloor$, a depender das probabilidades que o agente dá para os três possíveis estados da natureza.

Posto isso, faz-se necessário aqui a descrição de quatro possíveis situações teóricas.

\subsubsection{Utilidades iguais para os três estados de natureza}

Suponha que $\phi^{\prime V}(x)=\phi^{\prime E}(x)=\phi^{\prime D}(x)=\phi^{\prime}(x)$. Assim a escolha ótima independerá das probabilidades atribuídas pelo agente para a ocorrência de cada estado da natureza. Algebricamente, $x^{*}$ será o que resolve:

$$
\begin{gathered}
\pi^{V} \phi^{\prime V}(x)+\pi^{E} \phi^{\prime E}(x)+\left(1-\pi^{V}-\pi^{E}\right) \phi^{\prime D}(x)=p_{x} \Rightarrow \\
\pi^{V} \phi^{\prime}(x)+\pi^{E} \phi^{\prime}(x)+\left(1-\pi^{V}-\pi^{E}\right) \phi^{\prime}(x)=p_{x} \Rightarrow \\
\phi^{\prime}(x)=p_{x}
\end{gathered}
$$


Assim, para qualquer distribuição de probabilidades, se o preço do ingresso for mantido fixo, $x^{*}$ será sempre o mesmo, ou seja, o consumidor terá sempre o mesmo comportamento com relação a ir ou não ao estádio. Se $x^{*}>\theta$, tal indivíduo sempre irá ao estádio; caso contrário, nunca irá - chamaremos à frente a primeira situação de A1 e a segunda de A2. Graficamente, temos a Figura 2.

Figura 2 - Torcedor não se importa com o resultado do jogo

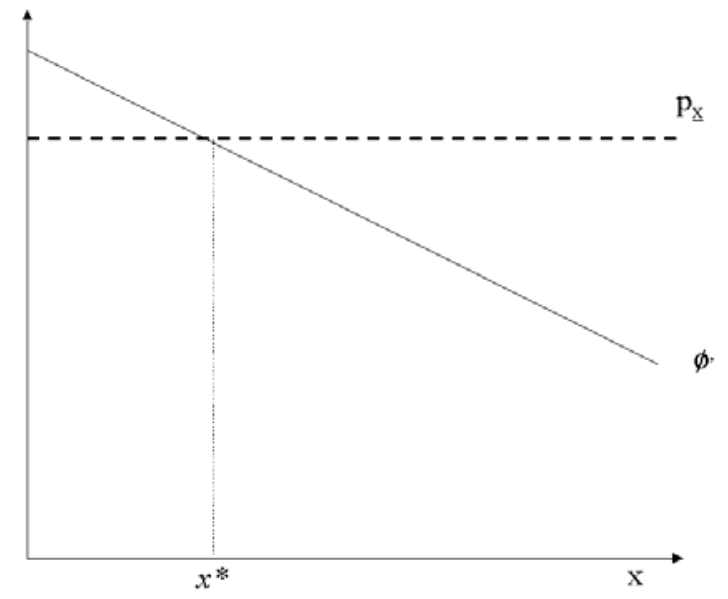

2.0.2. Utilidades diferentes para cada estado da natureza $\operatorname{com} \theta<x_{M I N}^{*}$

Tal situação ocorrerá no caso em que, mesmo que o torcedor tenha certeza da derrota de seu time, para ele a solução ótima será ir ao estádio. Assim, nesse caso, temos que $x^{*}$ também independe da probabilidade atribuída pelo agente a cada estado da natureza. Graficamente, temos a Figura 3, que ilustra estes indivíduos, doravante denominados por B1.

2.0.3. Utilidades diferentes para cada estado da natureza $\operatorname{com} \theta \geq x_{M A X}^{*}$

Esse caso ocorrerá quando mesmo tendo certeza da vitória de seu time, o torcedor escolhe não ir ao estádio. Assim, aqui também a escolha independe da distribuição de probabilidade para vitória, empate e derrota que o agente supõe. O comportamento destes indivíduos, denominados por B2, é ilustrado graficamente na Figura 4.

\subsubsection{Utilidades diferentes por estado de natureza com $\left.\theta \in] x_{M I N}^{*}, x_{M A X}^{*}\right]$}

Essa é a única situação em que o comportamento do agente é influenciado pela sua percepção das probabilidades de vitória, empate ou derrota de seu time. Se o vetor $\pi=\left[\pi^{V}, \pi^{E}, \pi^{D}\right]$ é tal que a solução para o problema do consumidor se dá além de $\theta$, a escolha será ir ao estádio; caso contrário, a escolha será não ir ao estádio. Graficamente, temos a Figura 5.

onde $h()=.\pi^{V} \phi^{\prime V}(x)+\pi^{E} \phi^{\prime E}(x)+\left(1-\pi^{V}-\pi^{E}\right) \phi^{\prime D}(x)$.

Nesse caso, está representado um consumidor que, para determinado jogo, devido às suas expectativas com relação à vitória, empate e derrota de seu time decide não ir ao jogo. Caso sua probabilidade 
Figura 3 - Torcedor sempre vai ao estádio

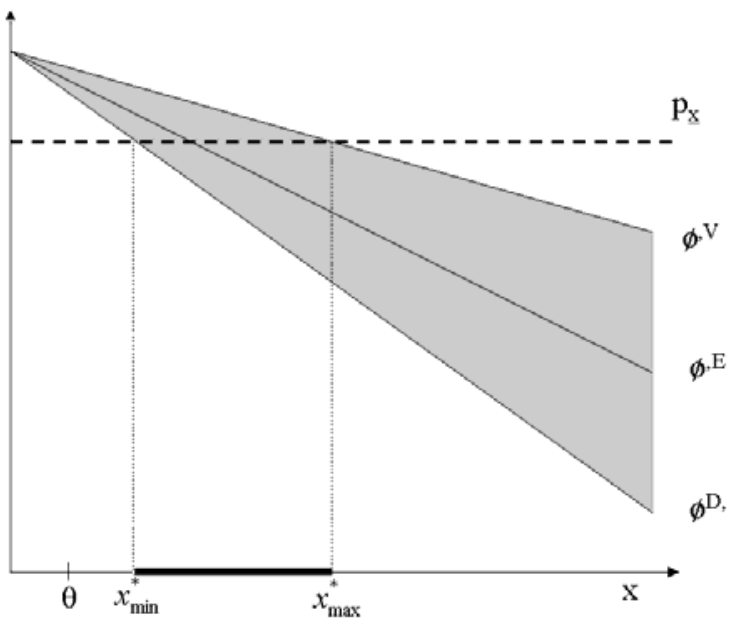

Figura 4 - Torcedor nunca vai ao estádio

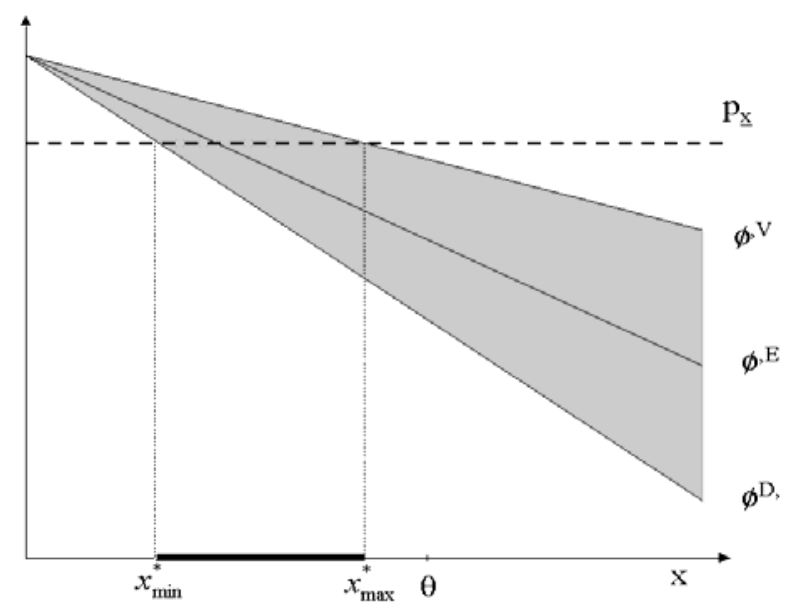


Figura 5 - Torcedor infiel

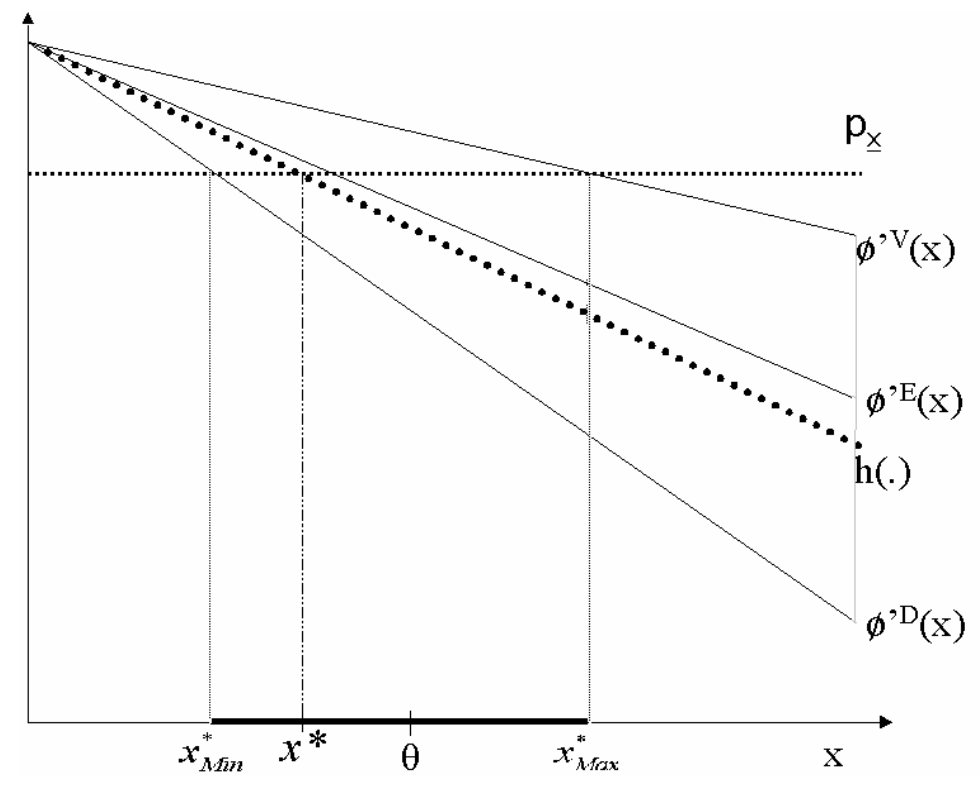

percebida de vitória aumentasse suficientemente, sua decisão se alteraria e tal consumidor decidiria ir ao jogo. Estes indivíduos serão designados como sendo do tipo $C$.

Descritas as cinco possíveis situações, A1, A2, B1, B2 e C, é possível agora definir de maneira precisa o que chamaremos neste trabalho por fidelidade. De imediato, sabemos que em uma torcida presente ao estádio, os indivíduos tipo A2 e B2 nunca se encontram, os indivíduos tipo A1 e B1 sempre se encontram e o indivíduo tipo $C$ às vezes se encontra. Deste modo, para qualquer jogo de qualquer time, os indivíduos encontrados no estádio serão ou A1, ou B1, ou C.

Assim, segue a definição:

Definição 2.1. Uma torcida é considerada infiel se e somente se entre os seus torcedores existirem indivíduos tipo C, ou seja, indivíduos cuja escolha sobre comprar ou não um jogo de futebol é dependente da sua percepção da probabilidade de seu time ganhar, empatar e perder.

Vale notar que a modelagem do problema da maneira aqui proposta, permite que cada torcedor possua sua função de utilidade esperada, bem como seu limiar de escolha para a variável latente e sua distribuição de probabilidade para os três estados da natureza. Além de esses três elementos poderem variar entre indivíduos, eles também podem variar para um mesmo indivíduo entre jogos. Por exemplo, um torcedor que seja do tipo B1 e, portanto, sua ida ao estádio não depende de sua expectativa sobre o resultado do jogo, pode em um determinado jogo escolher não ir ao estádio devido à chuva. O modelo cobre tal situação à medida que nesse determinado dia de chuva, as curvas de utilidade marginal desse torcedor se deslocariam para a esquerda até o ponto em que, para esse jogo especificamente, esse torcedor que é, sob nenhum choque aleatório, um tipo B1, se tornaria um tipo B2. No entanto, como será visto na seção econométrica, é possível identificar tais variações de comportamento aleatórias.

Assim sendo, o restante do presente trabalho terá como objetivo a identificação de indivíduos tipo $C$ entre as torcidas. Para isso, o que deve ser feito é tentar identificar as torcidas presentes nos estádios que variam de tamanho de acordo com alterações nas probabilidades que seus torcedores atribuem 
à vitória, empate e derrota de seu time. De acordo com a definição acima, caso tais torcidas sejam encontradas, elas serão classificadas como infiéis.

No entanto, uma dúvida que se apresenta é: como identificar torcedores que têm seu comportamento dependente do vetor de probabilidades $\pi$, se tal vetor não é observável? Para isso, surgirá uma solução econométrica: identificar-se-á variáveis observáveis que explicam a probabilidade de vitória, empate e derrota de um time. Com base nelas, será estimado um vetor de probabilidades para cada partida.

Portanto, a próxima seção, a qual entra na abordagem econométrica, primeiramente modelará a probabilidade de um time ganhar, empatar e perder e, em seguida, testará a existência de indivíduos tipo $C$ entre as torcidas.

\section{ESTIMAÇÃO E RESULTADOS}

Essa seção descreverá o procedimento de estimação e os principais resultados de nossa análise. Sucintamente, o procedimento compreende (i) a definição da amostra de times e jogos do campeonato brasileiro de 2004 a ser utilizada, (ii) a estimação das probabilidades de vitória, empate e derrota de cada um dos times da amostra nas partidas selecionadas (primeiro estágio) e (iii) a estimação do impacto destas probabilidades sobre o público das partidas consideradas (segundo estágio).

Assim sendo, em primeiro lugar é necessário ressaltar que a definição da amostra depende essencialmente da disponibilidade dos dados relativos ao público de cada partida. Neste sentido, uma vez que as informações contabilizadas pela CBF levam em conta apenas o público total da partida - separado por setor da arquibancada - e não o público de cada torcida, a amostra relevante foi selecionada com base nos seguintes critérios:

(i) Os times que disputaram o campeonato brasileiro de 2004 foram divididos em dois subgrupos. O primeiro, doravante chamado de grupo 1, contempla Atlético Mineiro, Botafogo, Corinthians, Cruzeiro, Flamengo, Fluminense, Grêmio, Internacional de Porto Alegre, Palmeiras, Santos, São Paulo e Vasco e o segundo contém os demais times (grupo 2);

(ii) Considerou-se então, apenas as partidas entre os doze times do grupo 1 contra os times do grupo 2 jogados na casa do time do grupo 1 .

A observância destes critérios, hipoteticamente, garante que o público total da partida seja em sua grande maioria composto por torcedores do time do primeiro grupo. Em linhas gerais, por razões óbvias, espera-se que o público de uma partida entre São Paulo e Goiás que foi disputada no Estádio do Morumbi seja primordialmente composto por torcedores do São Paulo. Desta maneira é possível superar o referido problema com os dados disponíveis.

Adicionalmente, é importante destacar que a medida de público utilizada leva em conta apenas o número de ingressos vendidos para a arquibancada, excluindo-se, portanto, os ingressos vendidos para cadeiras numeradas, geral, etc. Esta estratégia foi adotada tendo em vista que parte dos ingressos para cadeiras numeradas, por exemplo, pode ser distribuída gratuitamente pelos clubes em situações particulares. Na realidade, em rodadas decisivas do campeonato, times com baixo desempenho - muitas vezes tentando fugir do rebaixamento - distribuem ingressos de cadeiras numeradas para incentivar a ida do público ao estádio. Este comportamento, entretanto, tende a gerar viés no estimador de efeitos fixos que utilizamos no segundo estágio das estimações: sob esta lógica, o público de um time do grupo 1 passa também a ser explicado por um fator "não observável" (distribuição gratuita de ingressos) que está correlacionado com a variável explicativa de interesse ${ }^{2}$.

\footnotetext{
${ }^{2}$ Como ficará claro adiante a probabilidade de vitória utilizada para explicar o público depende do desempenho acumulado do clube até a rodada anterior.
} 
Com base nesta amostra foi utilizado um modelo Logit Ordenado para estimar as probabilidades de vitória, empate e derrota destes times em cada um dos jogos considerados. Traçando um paralelo com o modelo teórico, o que será feito aqui é, em primeiro lugar, definir algumas variáveis que explicam a probabilidade de um time perder, empatar e ganhar e, em seguida, através dessas variáveis, estimar o vetor de probabilidades $\pi$, definido na seção anterior. Vale notar, que no modelo teórico, cada torcedor possuía seu próprio vetor de probabilidades. Aqui, por razões de factibilidade, buscar-se-á um vetor representativo para todos os torcedores.

Uma possível alternativa seria simplesmente utilizar a base descrita acima para estimarmos o modelo e as probabilidades dos três estados da natureza. Acontece, entretanto, que este procedimento apresenta certa inconsistência: neste caso, os parâmetros que o torcedor utiliza para inferir as probabilidades de vitória, empate ou derrota do seu time na enésima rodada dependeriam também dos resultados de todas as partidas do campeonato de 2004, informação esta não disponível na enésima rodada. Em outras palavras, é razoável supor que o modelo utilizado pelo torcedor para a inferência das probabilidades de vitória, empate e derrota de seu time na enésima rodada não dependa de acontecimentos em rodadas futuras do campeonato, ou seja, suas expectativas são formadas sobre informações passadas.

A cada rodada do campeonato de 2004, portanto, é possível prever as probabilidades de vitória, empate e derrota dos 12 times do primeiro grupo através da estimação da seguinte forma funcional via um Logit Ordenado:

$$
P[y=j \mid X]=X \beta+\epsilon
$$

onde:

(i) $j=0,1$ ou2, para derrota, empate ou vitória, respectivamente.

(ii) A matriz $X$ contém as seguintes variáveis: dummy de jogo em casa (1 se é em casa, 0 cc); dummy para adversário grande (1 se adversário é considerado time grande, 0 cc); dummy para adversário pequeno (1 se adversário é pequeno, $0 \mathrm{cc}$ ); dummy para time grande (1 se time é grande, $0 \mathrm{cc}$ ); dummy para time pequeno (1 se time é pequeno, $0 \mathrm{cc}$ ) e desempenhos do time e do adversário acumulados até a rodada anterior (pontos ganhos sobre pontos disputados).

Assim, assume-se que o torcedor forma suas expectativas em qualquer rodada baseado em uma "janela" de resultados anteriores. Mais especificamente, considera-se que na enésima rodada o modelo probabilístico do torcedor dependa dos resultados (i) das cinco rodadas anteriores ou, (ii) das dez rodadas anteriores ou, (iii) das vinte rodadas anteriores ou, finalmente, (iv) das quarenta rodadas anteriores. Deste modo, para cada rodada do campeonato de 2004, o modelo levará em conta os resultados nas 5 , 10, 20 e 40 rodadas anteriores. Por exemplo, na primeira rodada de 2004 um modelo considerará as 5 últimas rodadas do campeonato de 2003, um outro modelo considerará os resultados das 10 últimas rodadas de 2003, o terceiro modelo considerará os resultados das 20 últimas rodadas de 2003 e finalmente o quarto modelo considera os resultados das 40 últimas rodadas de 2003. Na segunda rodada de 2004 o primeiro modelo considerará a primeira rodada de 2004 e as quatro últimas de 2003 e assim por diante para todas as rodadas de $2004 .^{3,4}$ No apêndice deste trabalho estão todos os parâmetros estimados para cada rodada de 2004 utilizando as janelas descritas acima.

\footnotetext{
${ }^{3}$ De maneira mais específica, a estimação dos parâmetros do Logit Ordenado levou em conta todos os jogos ocorridos em cada rodada - dadas as janelas - e não apenas as rodadas que continham times do grupo 1 contra os times do grupo 2 . Deste modo, o que fizemos foi estimar os parâmetros do Logit Ordenado com base em todas as rodadas (dentro de cada janela) e utilizar estes parâmetros para estimar as probabilidades dos três estados da natureza para as partidas consideradas na amostra do campeonato de 2004.

${ }^{4} \mathrm{Na}$ realidade, como na primeira rodada do campeonato o desempenho acumulado dos times não existe, excluímos esta rodada de nossa amostra.
} 
Posto isso, em consonância com o modelo teórico anteriormente apresentado, utilizou-se a razão entre a probabilidade de vitória e a probabilidade de derrota estimada através do modelo acima para explicar o público das partidas destes 12 times através de um estimador de efeitos fixos. A especificação deste modelo é dada pela equação abaixo:

$$
\begin{aligned}
\operatorname{Ln}\left(P_{u} b_{i t}\right)=\alpha_{0}+\sum_{i=1}^{12}\left[\alpha_{i} \operatorname{Ln}\left(\frac{\Pi v i t_{i t}}{\Pi d e r_{i t}}\right) * \text { Dtime }_{i}\right] \\
+\sum_{i=1}^{12} \beta_{i} \text { Dtime }_{i}+\sum_{t=1}^{41} \gamma_{t} \operatorname{Drodada}_{t}+\phi \operatorname{Ln}\left(p_{i t}\right)+\epsilon_{i t}
\end{aligned}
$$

Nesta equação, as variáveis podem ser descritas de acordo com o quadro abaixo:

Tabela 1 - Variáveis do Modelo de Efeitos Fixos

\begin{tabular}{|c|c|}
\hline Variável & Descrição \\
\hline Pub $_{i t}$ & Público da arquibancada do time $i$ na rodada $t$ \\
\hline$\Pi v i t_{i t}$ & Probabilidade de vitória do time $i$ na rodada $t$ \\
\hline$\Pi$ der & Pr \\
\hline Dtime $_{i}$ & Probabilidade de derrota do time $i$ na rodada $t$ \\
\hline Drodada $_{t}$ & Dummy para o time \\
\hline$p_{i t}$ & Dummy para a rodada \\
\hline
\end{tabular}

Vale lembrar que probabilidades de vitória e derrota a cada rodada do campeonato foram estimadas recursivamente - através de um modelo Logit Ordenado - de acordo com as janelas determinadas acima. O objetivo é testar a significância das interações entre as dummies de time e as probabilidades relativas de vitória. Conforme explicitado no modelo teórico, se o coeficiente deste termo for significante para um time $i$ qualquer, é possível inferir que existem nessa torcida indivíduos do tipo C. É importante ressaltar aqui que, o fato da torcida do time $i$ não conter indivíduos tipo $C$, não implica que o público presente no estádio não varie, mas sim que ele não varie de acordo com a expectativa com relação ao resultado do jogo.

Logo, se o coeficiente deste termo é significante para o time $i$, podemos dizer que a torcida deste time é infiel - de acordo com a definição de fidelidade apresentada (existem nela indivíduos tipo C). Caso contrário, quando o referido coeficiente é insignificante, considera-se que a torcida deste time é fiel.

Além disso, com relação à hipótese de identificação do modelo, assume-se que a variável de interação entre probabilidades relativas e dummy de time, uma vez que controlamos pela dummy de time (efeito fixo), não está correlacionada com nenhum outro fator que também explique público. De fato, dado que estas probabilidades na enésima rodada dependem essencialmente do desempenho dos times até a rodada anterior, é razoável afirmarmos que esta variável só está correlacionada, na enésima rodada, com o efeito fixo do clube - para um time qualquer.

Resumidamente, quando se considera janelas de 40 jogos, todas torcidas são estatisticamente fiéis. Para 20 jogos, Grêmio e Internacional têm torcidas infiéis a 5\%, enquanto a torcida do Atlético MG é infiel a 10\%. Para as memórias de 10 e 5 jogos apenas Atlético MG possui torcida infiel, a 10\% e 5\%, respectivamente. ${ }^{5}$ Os resultados são apresentados nas tabelas seguintes, onde os coeficientes presentes são os $\alpha_{1}, \alpha_{2}, \ldots, \alpha_{12}$, da equação 7 :

\footnotetext{
${ }^{5} \mathrm{O}$ desvio-padrão associado à variável de probabilidade é estimado com viés em virtude da predição da variável explicativa em uma regressão anterior. No entanto, a correção do desvio-padrão não é trivial. Para contornar essse problema, ao menos
} 
Bruno Giovannetti, Bruno de Paula Rocha, Fábio Miessi Sanches, José Carlos D. da Silva

\begin{tabular}{|l|l|l|}
\hline \multicolumn{3}{|c|}{ Memória 05 } \\
\hline Times & Coeficientes & p-valor \\
\hline Atletico MG & 0,626 & 0,051 \\
\hline Botafogo & $-0,028$ & 0,939 \\
\hline Corinthians & 0,025 & 0,834 \\
\hline Cruzeiro & 0,008 & 0,967 \\
\hline Flamengo & 0,221 & 0,280 \\
\hline Fluminense & $-0,319$ & 0,266 \\
\hline Grêmio & 0,104 & 0,596 \\
\hline Internacional & 0,398 & 0,119 \\
\hline Palmeiras & $-0,143$ & 0,488 \\
\hline Santos & $-0,062$ & 0,857 \\
\hline São Paulo & 0,004 & 0,983 \\
\hline Vasco & 0,131 & 0,701 \\
\hline Preço & $-1,310$ & 0,004 \\
\hline \multicolumn{3}{|c|}{ Rúmero de obs.: 121} \\
\hline \multicolumn{3}{|c|}{0.8542} \\
\hline
\end{tabular}

\begin{tabular}{|l|l|l|}
\hline \multicolumn{3}{|c|}{ Memória 10 } \\
\hline Times & Coeficientes & p-valor \\
\hline Atletico MG & 0,814 & 0,023 \\
\hline Botafogo & $-0,248$ & 0,379 \\
\hline Corinthians & $-0,025$ & 0,872 \\
\hline Cruzeiro & $-0,087$ & 0,703 \\
\hline Flamengo & 0,287 & 0,262 \\
\hline Fluminense & $-0,292$ & 0,310 \\
\hline Grêmio & 0,303 & 0,290 \\
\hline Internacional & 0,467 & 0,148 \\
\hline Palmeiras & $-0,303$ & 0,220 \\
\hline Santos & 0,017 & 0,974 \\
\hline São Paulo & 0,077 & 0,731 \\
\hline Vasco & 0,070 & 0,862 \\
\hline Preço & $-1,372$ & 0,003 \\
\hline \multicolumn{3}{|c|}{ Rúmero de obs.: 121} \\
\hline \multicolumn{2}{|c|}{0.8602} \\
\hline
\end{tabular}

\begin{tabular}{|l|l|l|}
\hline \multicolumn{3}{|c|}{ Memória 20 } \\
\hline Times & Coeficientes & p-valor \\
\hline Atletico MG & 0,575 & 0,072 \\
\hline Botafogo & $-0,088$ & 0,781 \\
\hline Corinthians & $-0,022$ & 0,913 \\
\hline Cruzeiro & $-0,172$ & 0,450 \\
\hline Flamengo & 0,357 & 0,254 \\
\hline Fluminense & $-0,243$ & 0,472 \\
\hline Grêmio & 0,604 & 0,035 \\
\hline Internacional & 0,875 & 0,034 \\
\hline Palmeiras & $-0,406$ & 0,154 \\
\hline Santos & 0,174 & 0,859 \\
\hline São Paulo & 0,168 & 0,554 \\
\hline Vasco & $-0,063$ & 0,879 \\
\hline Preço Número de obs.: 121 \\
\hline \multicolumn{3}{|c|}{ R2: 0.8618} \\
\hline \multicolumn{3}{|c|}{$-1,583$} \\
\hline
\end{tabular}

\begin{tabular}{|l|l|l|}
\hline \multicolumn{3}{|c|}{ Memória 40 } \\
\hline Times & Coeficientes & p-valor \\
\hline Atletico MG & 0,328 & 0,163 \\
\hline Botafogo & $-0,217$ & 0,530 \\
\hline Corinthians & 0,006 & 0,974 \\
\hline Cruzeiro & $-0,229$ & 0,406 \\
\hline Flamengo & 0,265 & 0,371 \\
\hline Fluminense & $-0,094$ & 0,709 \\
\hline Grêmio & 0,447 & 0,162 \\
\hline Internacional & 0,989 & 0,151 \\
\hline Palmeiras & $-0,214$ & 0,505 \\
\hline Santos & 0,112 & 0,889 \\
\hline São Paulo & $-0,029$ & 0,892 \\
\hline Vasco & $-0,104$ & 0,802 \\
\hline Preço Número de obs.: 121 \\
\hline \multicolumn{3}{|c|}{ R2: 0.8500} \\
\hline \multicolumn{3}{|c|}{$-1,586$} \\
\hline
\end{tabular}




\section{CONCLUSÃO}

O presente estudo apresentou dois objetivos principais. O primeiro, mais geral, consistiu em procurar ser um dos poucos trabalhos feitos no país que tratam de temas relacionados ao esporte profissional, mais especificamente ao futebol, através de um tratamento baseado no arcabouço teórico econômico. Os autores deste pensam que, dada a importância econômica e social que o futebol possui no país, o que pode ser denominada "economia do futebol" seria uma área muito importante a ser desenvolvida. Estamos convencidos de que tal área é não somente fértil em possíveis temas de estudo como também promissora de resultados relevantes, tanto para os clubes e dirigentes como para o bem estar dos torcedores.

O segundo, mais específico, buscou tocar, de maneira pioneira, num constante tema do esporte nacional, qual seja, a fidelidade das torcidas. Para isso, modelamos teoricamente o comportamento do torcedor através da abordagem microeconômica de utilidade esperada. Feito isso, definimos o conceito de fidelidade de uma torcida e, via técnicas econométricas, mais precisamente um Logit Ordenado e um Painel com Efeitos Fixos, testamos tal conceito com base em dados de freqüência ao estádio das torcidas de doze grandes times nacionais, no Campeonato Brasileiro de 2004. Chegamos assim à conclusão de que, naquele campeonato, as torcidas foram predominantemente fiéis, com a exceção apenas das torcida dos clubes Atlético Mineiro, Internacional de Porto Alegre e Grêmio.

\section{Referências Bibliográficas}

Amador, R. P. (2004). Avaliação e empresas: Uma aplicação aos clubes de futebol. Dissertação de mestrado, UnB, UFPB, UFPE e UFRN, Brasília. Dissertação de mestrado defendida pelo Programa Multiinstitucional e Inter-regional de Pós-Graduação em Ciências Contábeis.

Araújo Jr., A. F., Shikida, C. D., \& Monasterio, L. M. (2003). Abrindo a 'caixinhas de surpresas': Uma análise econométrica do futebol brasileiro. Technical Report 3, IBMEC/MG.

Dobson, S. \& Goddard, J. (2001). The economics of football. Cambridge University Press.

Mas-Colell, A., Whinston, M. D., \& Green, J. R. (1995). Microeconomic Theory. Oxford University Press.

Melo, L. M. (2003). Football in the Americas, chapter Brazilian Football: Technical Success and Economic Failure? ISA, Londres.

Neale, W. C. (1964). The peculiar economics of professional sports. The Quarterly Journal of Economics, 79:1-14.

Neumann, J. V. \& Morgenstern, O. (1944). Theory of Games and Economic Behavior. Princeton University Press.

Rottenberg, S. (1956). The baseball players labor market. Journal of Political Economy, 64:242-258.

Shikida, C. D. \& Shikida, P. F. A. (2004). É o futebol o ópio do povo? uma abordagem econômica preliminar. Technical Report 19, IBMEC/MG.

Sloane, P. J. (1971). The economics of professional football: The football club as a utility maximiser. Scottish Journal of Political Economy, 18(2):121-46. available at http://ideas.repec . org/a/bla/ scotjp/v18y1971i2p121-46.html.

parcialmente, estimou-se o desvio-padrão Boostrap no segundo estágio da estimação. Foram utilizadas 1000 réplicas Bootstrap por reamostragem e os resultados obtidos corroboram integralmente as conclusões acima. 
Bruno Giovannetti, Bruno de Paula Rocha, Fábio Miessi Sanches, José Carlos D. da Silva

Souza, F. A. P. d. (2004). Um estudo sobre a demanda por jogos de futebol nos estádios brasileiros. Dissertação de mestrado, Departamento de Administração da Faculdade de Economia, Administração e Contabilidade da USP.

\section{A. APÊNDICE}




\section{rbe}

Medindo a fidelidade das torcidas brasileiras: uma análise econômica no futebol

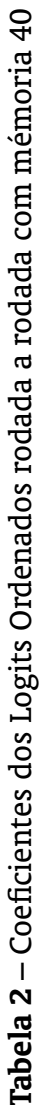

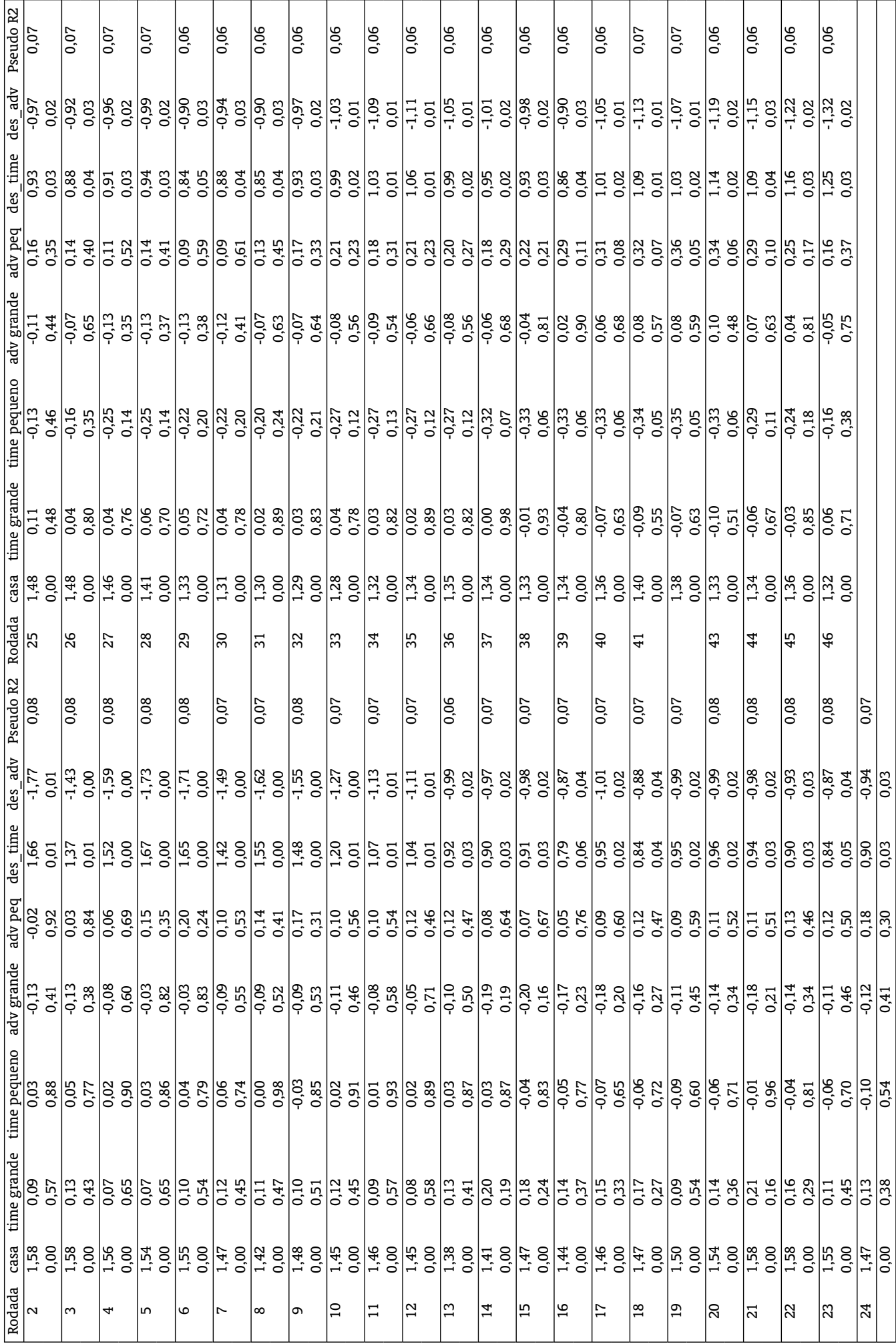

RBE Rio de Janeiro v. 60 n. 4/p. 389-406 Out-Dez 2006 


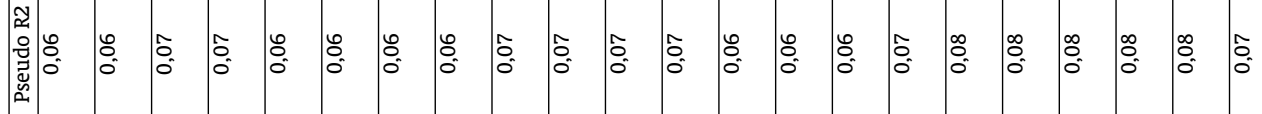

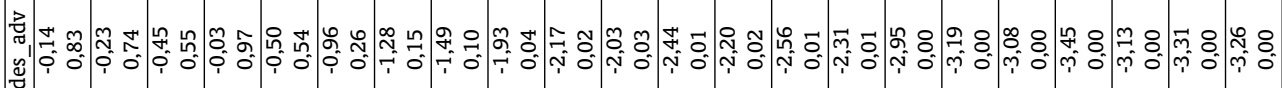

ชิ

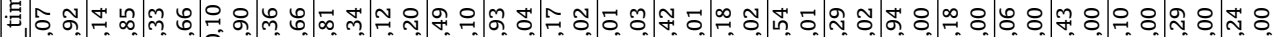
$\mathscr{\mho}^{\prime \prime}$

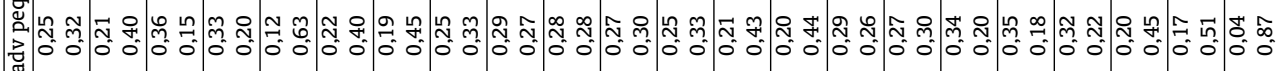

○行

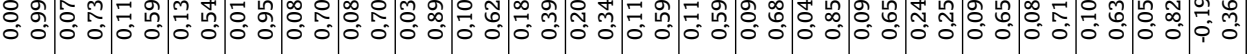
엻

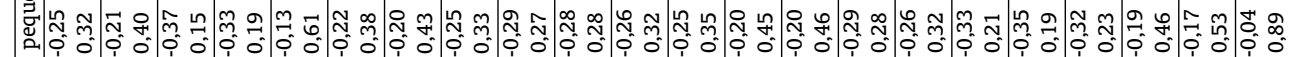
宜

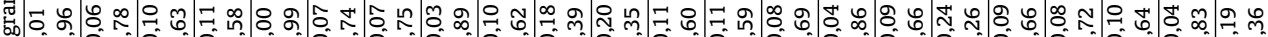

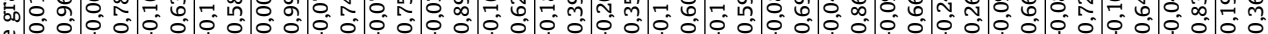

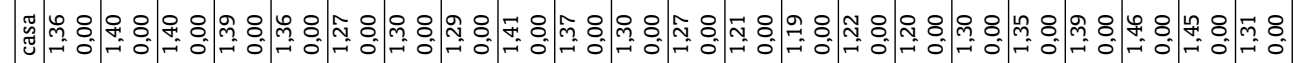
゚

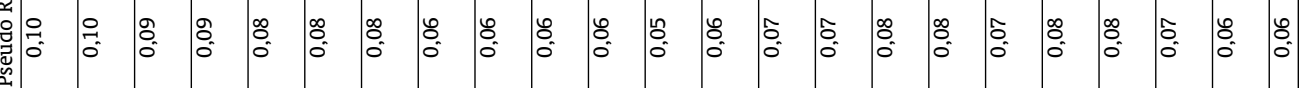
オ.

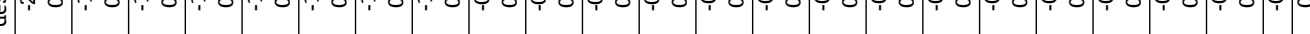
自年 要

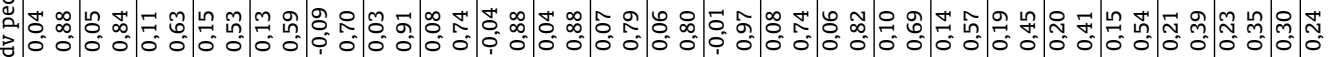

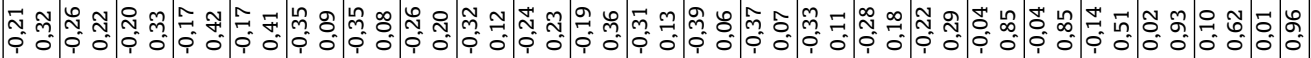
:

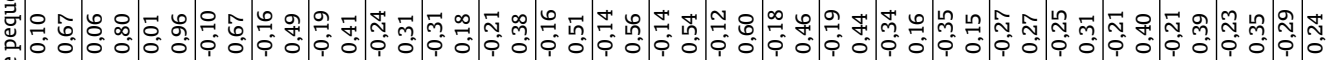
具

ำ

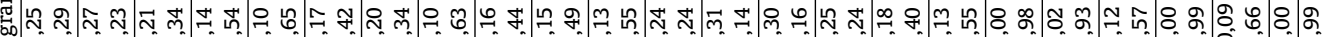

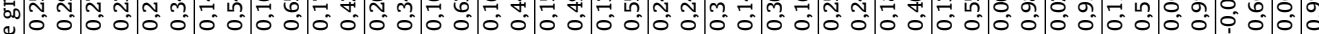

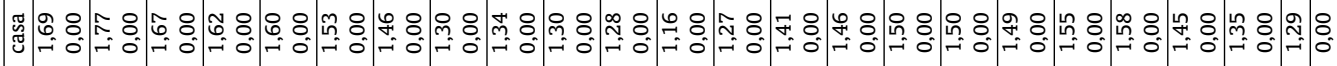
荵

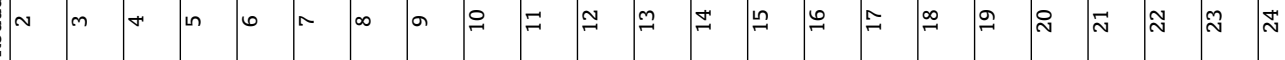




\section{rbe}

Medindo a fidelidade das torcidas brasileiras: uma análise econômica no futebol

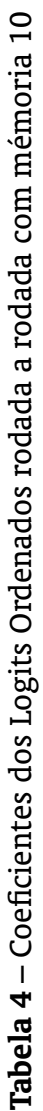

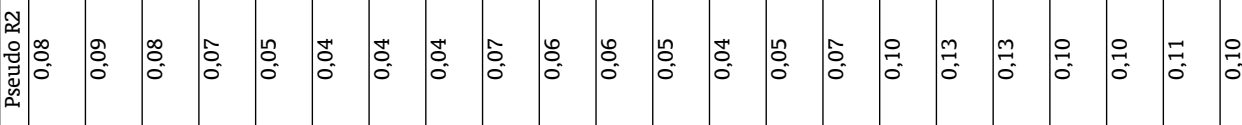

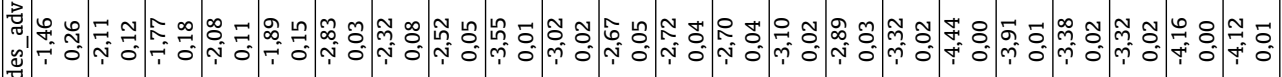

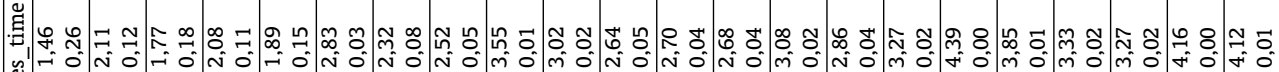

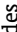

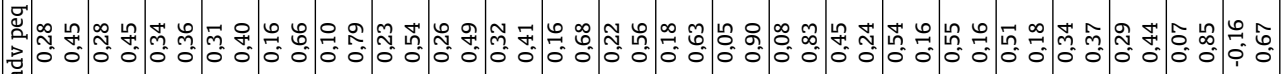
$\because$

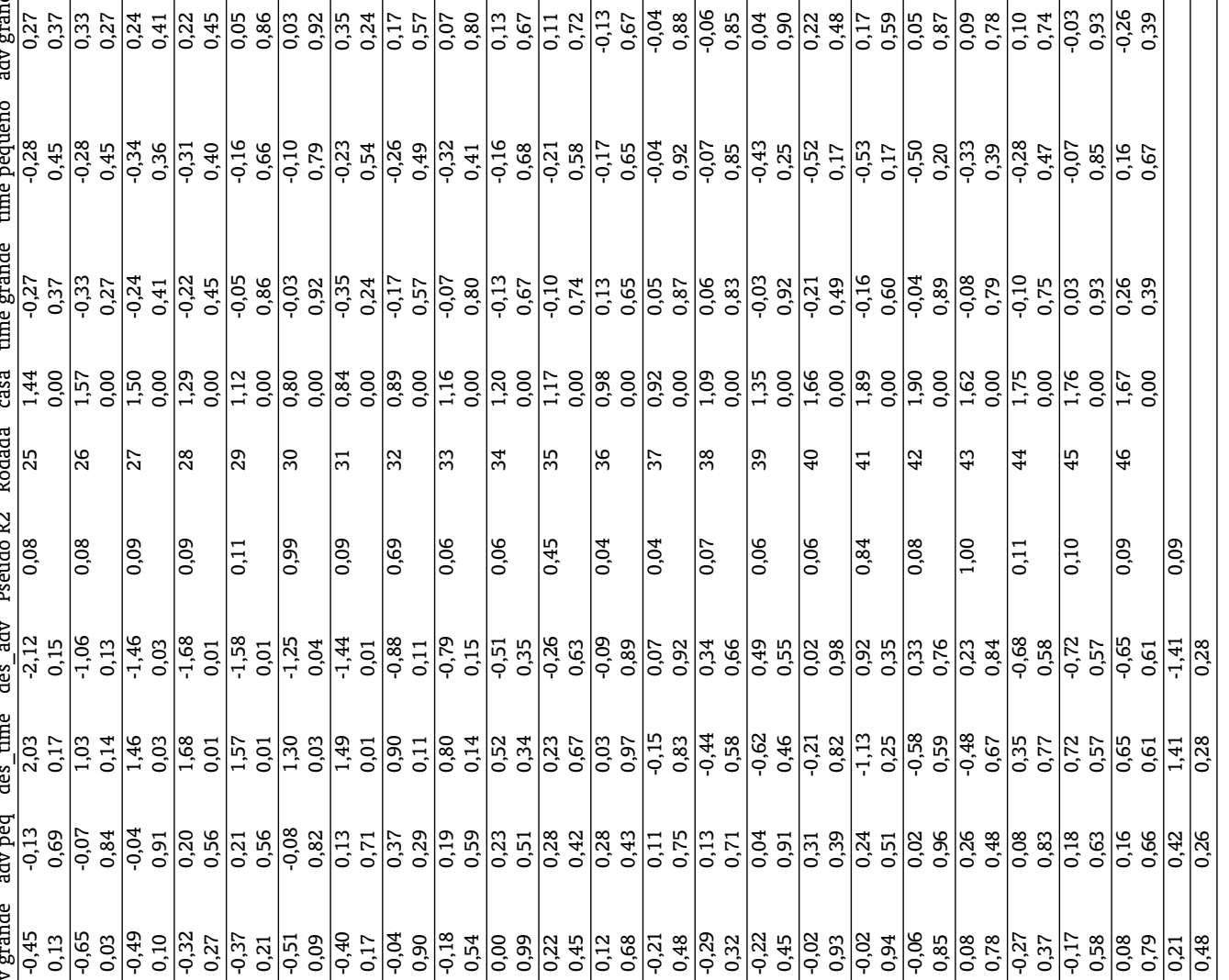
西

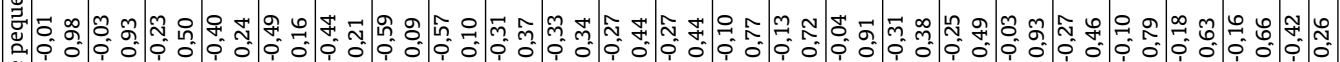
:

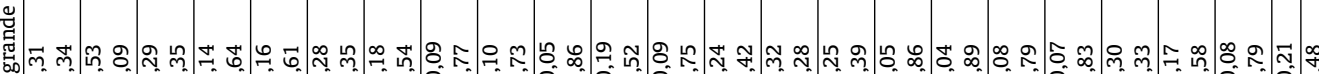

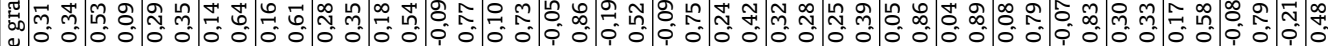
:

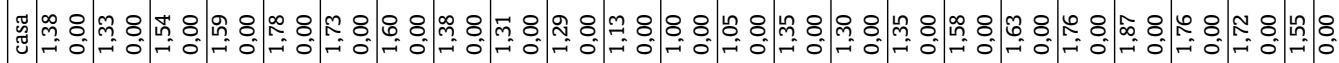

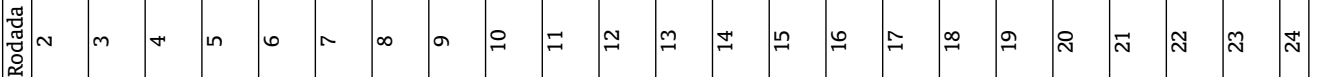




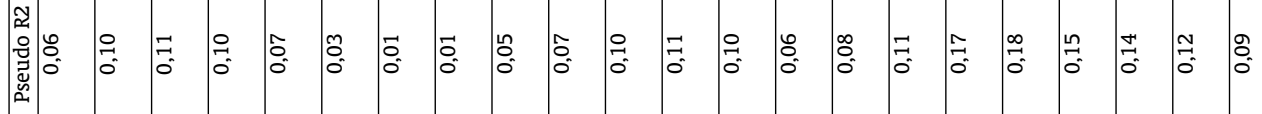

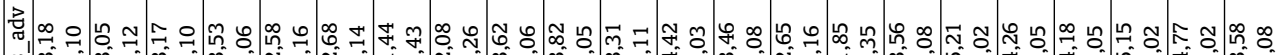
若

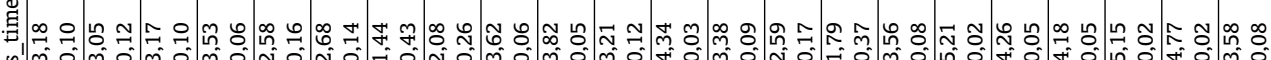

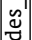

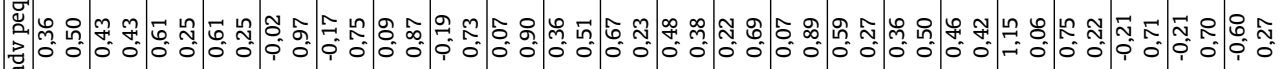

讨

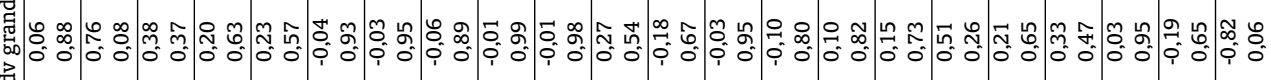

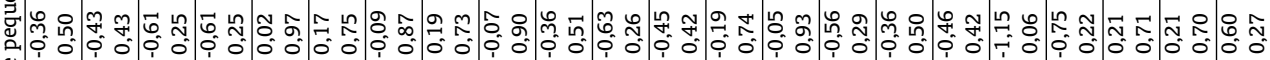

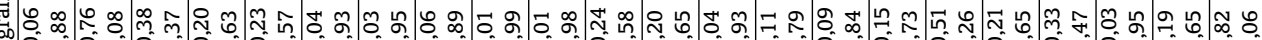
药

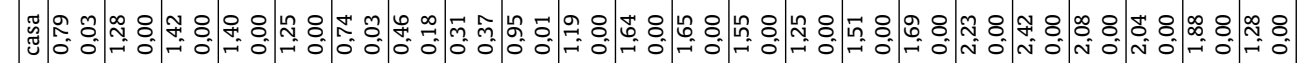
⿹弋山

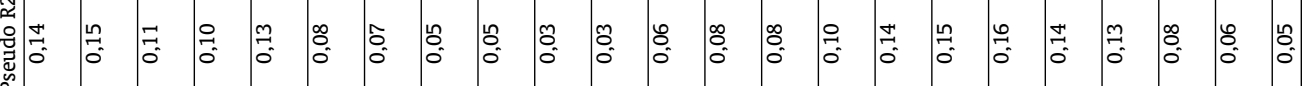

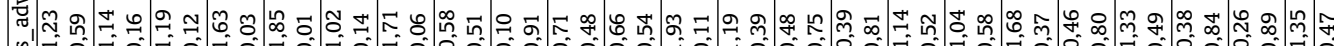

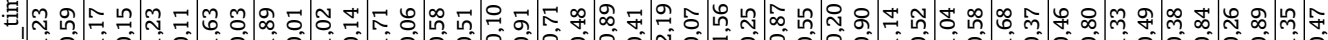
"ू.

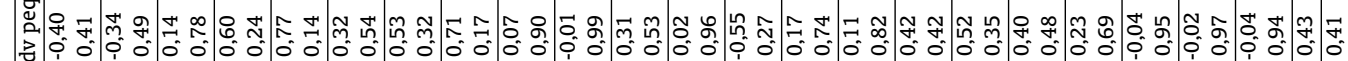

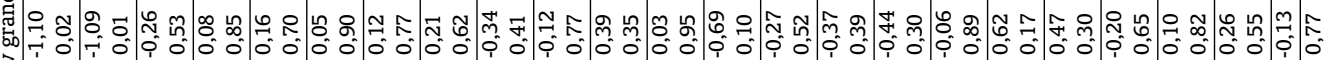
ㄱ.

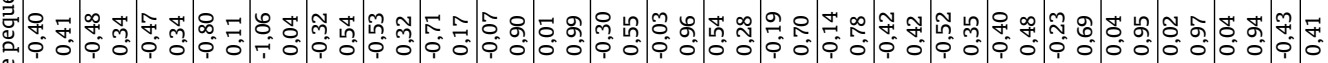
罗

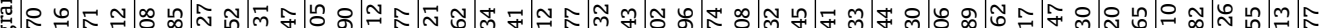

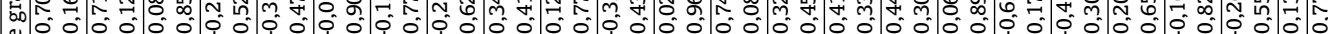

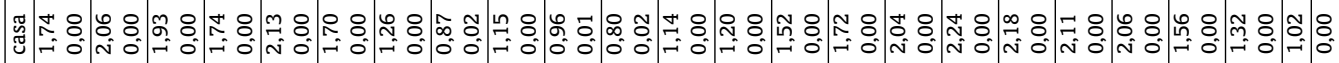

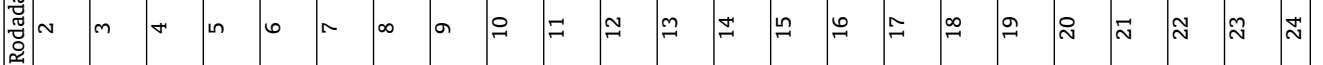

